\title{
Fatigue life extension by electroless nickel infiltration plating
}

\author{
C.S. Shin *, Z.Z. Chen \\ Department of Mechanical Engineering, National Taiwan University, No. 1, Sec. 4, Roosevelt Road, Taipei 10617, Taiwan, ROC
}

Received 8 January 2001; received in revised form 24 April 2001; accepted 26 April 2001

\begin{abstract}
Introducing artificial closure material into a fatigue crack has been shown to be able to retard the crack and give considerable life extension. Most of the previous work employed polymers as closure material which will disintegrate under a high service temperature. Moreover, infiltrations of these closure materials were made with the cyclic loading interrupted and the cracks held open at some static load. This will give an intense initial retardation. However, retardation will die down quickly if it is not severe enough to arrest the crack right away. To improve on the above drawbacks, the current work employed electroless nickel-plating as closure material. A more efficient infiltration method has been developed to allow on-line infiltration plating without interrupting the cyclic loading. To shed more light on the possible applicability of this technique to practical service loading, the retardation behaviour under different static infiltration loads, different load ratios, variations in loading history and loading frequencies have been investigated. It has been found that by combining static and dynamic infiltration plating, a fatigue crack can be brought to arrest quickly even under a loading frequency of $10 \mathrm{~Hz}$. ( 2001 Elsevier Science Ltd. All rights reserved.
\end{abstract}

Keywords: Crack infiltration; Dynamic infiltration; Artificial crack closure; Crack arrest; Fatigue damage repair; Life extension

\section{Introduction}

It is well known that a tensile overload can bring about fatigue crack growth retardation (e.g. [1]). The mechanisms underlying overload retardation may be varied [2-8] yet plasticity-induced premature crack closure stands out to be one of the most significant mechanisms [9-11]. Namely, residual plastic deformation leaves behind extra material on the crack flanks, causing premature crack closure and reduction in the effective crack driving force. The above observation suggests that if we can induce extra closure without applying a tensile overload, the growth of fatigue damage may still be checked. In fact, it has been shown that infiltration of foreign materials into a fatigue crack may induce crack growth retardation and even crack arrest [12-18]. Quantitative models for predicting the outcome of infiltration have also been put forward $[16,19,20]$. It is apparent that this infiltration method has the potential to be developed into a practical fatigue repair technique.

It has been shown that for this technique to be effec-

\footnotetext{
* Corresponding author. Tel.: +886-2-2362-2160.

E-mail address: csshin@ccms.ntu.edu.tw (C.S. Shin).
}

tive, the infiltrant must get as close to the crack tip as possible $[16,17,20]$. To achieve this end the artificial closure materials should have a low viscosity and surface tension so that it can penetrate into small fissures easily yet it must be able to transform into a state which has enough stiffness to withstand the compressive loading from the closing crack. Furthermore, it should be able to remain stable in the working environment. Convenient choices are precursors of polymeric materials that can harden on curing. In fact the most commonly employed infiltrant material is epoxy resin $[15,17,18,21-24]$. The viscosity of the resin is a little high and it cannot flow into small fissures easily. Hence in most of the above works, infiltrate coverage of the fracture surface was often only partial $[16,23]$ and probably varied from test to test. The reproducibility of the retardation results was therefore not very good. Raising the temperature of the resin may increase the flowability [25]. However, epoxy is only stable below about $150^{\circ} \mathrm{C}$ for prolonged use.

Electro- and electroless plating of nickel as a closure material $[16,26,27]$ has been attempted. Nickel infiltration has advantages over epoxy in that it may be used under much higher service temperatures and that the aqueous electrolyte has a lower viscosity. However, URRehman and Thomason [16] found that nickel plating 


\section{Nomenclature}

$C, m$ Constants in the Paris law

$C_{\mathrm{e}}, m_{\mathrm{e}}$ Constants in the Elber modification of the Paris law

ILL Infiltration load level, as a fraction of maximum load

$K_{\max } \quad$ Maximum stress intensity applied in the cyclic loading

$K_{\min } \quad$ Minimum stress intensity applied in the cyclic loading

$K_{\text {op }} \quad$ The stress intensity at which a fatigue crack become fully open

$R_{0} \quad$ original load ratio (=min. load/max. load)

$R^{\prime} \quad$ New load ratio used after a crack has been grown under $R_{0}$ for a period

$U \quad$ Fraction of applied stress intensity range for which the crack is open

$\Delta K \quad$ Applied stress intensity range

$\Delta K_{\text {eff }}$ Effective stress intensity range for which the crack is open

was spongy and so the infiltrated wedge did not possess enough stiffness to bring about effective crack closure. Its retardation effect was therefore inferior to that achieved by polymeric infiltrants. Considerably better retardation results were reported by Song et al. [26,27]. This discrepancy may be caused by inefficient infiltration methods and improper plating conditions. Previous works invariably did the infiltration while the fatigue crack was held open by a static load. In the current work, a further improved method for infiltration has been developed which allows concurrent plating while the cyclic loading is being applied. The resulting development of growth retardation under different static loading conditions and dynamic cycling has been investigated.

\section{Experimental procedures}

Compact tension specimens of width $50 \mathrm{~mm}$ and thickness $6 \mathrm{~mm}$ were machined from a 7075-T651 sheet stock. Fatigue tests were carried out on an MTS 810 closed-loop servo-hydraulic machine. Sinusoidal waveform was used. The nominal frequency was $15 \mathrm{~Hz}$ unless under controlled frequency tests. Crack length was monitored using a travelling microscope to a resolution of $0.01 \mathrm{~mm}$. Manual load shedding was employed to maintain a constant baseline $\Delta K$ of $7 \mathrm{MPa} \sqrt{m}_{m}$ throughout the tests. $R$ ratios ( $\mathrm{min}$. load/max. load) of $0.1,0.3$ and 0.5 were employed in different tests.

After a crack growth of about $5 \mathrm{~mm}$ from the starter notch, the growth rate and crack closure responses have both settled down well to steady state values. The test was then interrupted and a $2.8 \mathrm{~mm}$ hole was drilled from the top through half the specimen height to slightly below the fracture surface. Infiltration with an electroless nickel-plating solution was then carried out either in the static or dynamic modes. The plating solution was kept at $95^{\circ} \mathrm{C}$ with a heater to enable optimum plating. In the static mode, the crack was held open at different infiltration load levels $\left(0.95,1.2\right.$ and $\left.1.5 K_{\max }\right)$ by inserting an alumina wedge into the crack mouth at the desired load. The specimen was then removed from the testing machine and nickel plating solution was forced through the specimen hole with bottled nitrogen at a pressure of 1 to $5 \mathrm{~atm}$. Solution dripping out from the specimen was collected in a tank and a re-circulation circuit was thus set up. The infiltration process was interrupted when the plating solution stopped seeping from the crack. The whole infiltration process typically took about 4 to 5 hours, depending on the $R$ ratio and the propping load during infiltration. In the dynamic mode, infiltration was done with fatigue testing going on at the chosen loading frequencies of 1,5 and $10 \mathrm{~Hz}$ while the $R$ ratio was kept at 0.1. Details about the combination of load ratios, infiltration modes and infiltration parameters that have been tested are summarized in Table 1 .

During the fatigue tests, the crack opening load was monitored by a compliance method aided by an offset procedure proposed by Kikukawa et al. [28]. The relevant displacement for compliance information was measured with a back face strain gage. The gage output was also closely monitored throughout the wedge insertion and infiltration process to ensure that no unwanted overload had been induced. A low pass filter with a cutoff frequency of $1 \mathrm{~Hz}$ was used to reduce electrical noises. As a result, the testing frequency was reduced to $0.05 \mathrm{~Hz}$ during closure measurement to avoid signal distortion. The degree of crack closure, $U$, was defined as the fraction of the load range for which the crack is open.

$U=\frac{K_{\max }-K_{\mathrm{op}}}{K_{\max }-K_{\min }}=\frac{\Delta K_{\mathrm{eff}}}{\Delta K}$

where $K_{\text {op }}$ is the stress intensity at which the crack started to become fully open and $\Delta K_{\text {eff }}$ is the effective range of stress intensity available for growing a crack. This point is identified by the first departure from linearity on the offset load-back face strain trace. Since a fatigue crack opens in a progressive manner, the curvature of the load-strain trace changes gradually and this 
Table 1

Details of the test matrix

\begin{tabular}{|c|c|c|c|}
\hline Infiltration mode & $R$ ratio & Infiltration load level $\left(K_{\max }\right)$ & Remarks \\
\hline \multirow[t]{9}{*}{ Static } & \multirow[t]{3}{*}{0.1} & 0.95 & Repeated thrice \\
\hline & & 1.2 & $\begin{array}{l}\text { Crack arrested, growth resumed } \\
\text { at } R^{\prime}=0.2\end{array}$ \\
\hline & & 1.5 & $\begin{array}{l}\text { Crack arrested, growth resumed } \\
\text { at } R^{\prime}=0.3\end{array}$ \\
\hline & \multirow[t]{3}{*}{0.3} & 0.95 & \multirow{3}{*}{$\begin{array}{l}\text { Crack arrested, growth resumed } \\
\text { at } R^{\prime}=0.4\end{array}$} \\
\hline & & 1.2 & \\
\hline & & 1.5 & \\
\hline & \multirow[t]{3}{*}{0.5} & 0.95 & \multirow{3}{*}{$\begin{array}{l}\text { Crack arrested, growth resumed } \\
\text { at } R^{\prime}=0.6 .\end{array}$} \\
\hline & & 1.2 & \\
\hline & & 1.5 & \\
\hline \multirow{3}{*}{$\begin{array}{l}\text { Static (employed higher } R \text { ratio after } \\
\text { infiltration) }\end{array}$} & 0.2 & 0.95 & \multirow{3}{*}{$\begin{array}{l}\text { Precracked at } R=0.1 \text { before } \\
\text { infiltration, the higher } R \text { was then } \\
\text { employed immediately after } \\
\text { infiltration }\end{array}$} \\
\hline & $0.2 / 0.3$ & 1.2 & \\
\hline & 0.3 & 1.5 & \\
\hline \multirow[t]{3}{*}{ Dynamic } & \multirow[t]{3}{*}{0.1} & - & $1 \mathrm{~Hz}$ \\
\hline & & - & $5 \mathrm{~Hz}$ \\
\hline & & - & $10 \mathrm{~Hz}$ \\
\hline \multirow[t]{3}{*}{ Static+Dynamic $(10 \mathrm{~Hz})$} & 0.1 & 0.95 , once & - \\
\hline & 0.1 & 0.95 , two times & $\begin{array}{l}\text { Crack arrest after the second } \\
\text { static infiltration }\end{array}$ \\
\hline & 0.1 & Random, between 0.1 to $1 K_{\max }$ & $\begin{array}{l}\text { Alternate static and dynamic } \\
\text { infiltration, at } 7500 \text { cycles } \\
\text { interval. Crack arrested after } 7 \\
\text { repetitions. }\end{array}$ \\
\hline
\end{tabular}

imposes some uncertainty on the location of this point. It is estimated such uncertainty corresponds to a range of 0.05 in the $U$ value.

\section{Results and discussion}

\subsection{Baseline fatigue crack propagation data}

Fatigue crack growth rate is commonly related to the stress intensity range $\Delta K$ through Paris' law:

$\frac{d a}{d N}=C(\Delta K)^{m}$

Elber [8] suggested taking premature crack closure into account. In this case, the crack growth rate may be correlated through

$\frac{d a}{d N}=C_{\mathrm{e}}\left(\Delta K_{\mathrm{eff}}\right)^{m_{\mathrm{e}}}$

where $d a / d N$ is in $\mathrm{mm} /$ cycle, $\Delta K_{\text {eff }}$ and $\Delta K$ in MPa $\sqrt{ }_{m}$. The crack growth data of the current specimen material can be piecewise fitted to the above equations in three stages. Table 2 gives the values of the fitted parameters and the applicability ranges for each stage.

Different infiltration conditions and infiltrants caused crack growth retardation to different extents. The most straightforward parameter to quantify the beneficial effect of a retardation is the amount of life extension expressed in number of cycles. The amount of life extension is computed by the difference between the actual number of cycles elapsed for crack growth to return to steady state and the cycle elapsed if the crack had grown at the constant baseline rate throughout. The severity of maximum retardation can be described by a retardation ratio (minimum growth rate/baseline growth rate). The overall retardation affected crack growth increment also affects the amount of a life extension. Finally, previous tests have shown that with reliable infiltration methods, the minimum $U$ value induced by the infiltration will predict whether a repair is going to be successful or not [17]. These four parameters will be used to quantify the following retardation results.

\subsection{Retardation caused by prop-opening load alone}

During static mode infiltration, the fatigue crack will be propped open with load ranging from 0.95 to 1.5 
Table 2

The constants and exponents for Paris' law and Elber's modification

\begin{tabular}{|c|c|c|c|c|}
\hline \multirow[t]{3}{*}{ Paris' law } & $\Delta K\left(\mathrm{MPa} \sqrt{ }_{m}\right)$ & $\Delta K<5.7$ & $5.7<\Delta K<7$ & $7<\Delta K<10$ \\
\hline & $C$ & $8.1145 \times 10^{-7}$ & $4.5437 \times 10^{-14}$ & $9.3745 \times 10^{-8}$ \\
\hline & $m$ & 1.6620 & 11.195 & 3.6076 \\
\hline \multirow[t]{3}{*}{ Elber's modification } & $\Delta K_{\text {eff }}(\mathrm{MPa} \sqrt{ } m)$ & $\Delta K_{\mathrm{eff}}<5$ & $5<\Delta K_{\text {eff }}<6.5$ & $6.5<\Delta K_{\mathrm{eff}}<9.1$ \\
\hline & $C_{\mathrm{e}}$ & $2.1735 \times 10^{-6}$ & $5.4467 \times 10^{-12}$ & $1.0939 \times 10^{-6}$ \\
\hline & $m_{\mathrm{e}}$ & 1.2067 & 9.2256 & 2.5936 \\
\hline
\end{tabular}

times the maximum applied stress intensity $\left(K_{\max }\right)$ for several hours. These opening loads may produce a certain extent of crack tip blunting and may thus induce overload retardation effect. To assess the possible degree of retardation so caused, a specimen was tested after being subjected to the propping loads alone.

The baseline crack propagation rate at an applied constant $\Delta K$ of $7 \mathrm{MPa} \sqrt{ } m$ was about $1 \times 10^{-4} \mathrm{~mm} /$ cycle. Propping open at $0.95 K_{\max }$ for five hours did not cause any observable change in the fatigue crack growth behaviour. Propping open the specimen at $1.2 K_{\max }$ caused a slight immediate acceleration while at $1.5 K_{\max }$ there was a small but marked acceleration to $\sim 2.5 \times 10^{-4}$ $\mathrm{mm} /$ cycle on resumption of the baseline cyclic loading. Thereafter, growth rate decreased steeply to $\sim 80 \%$ and $\sim 70 \%$ of the baseline rate respectively. This was followed by gradual acceleration back to the steady baseline state. Fig. 1 shows the typical disturbances in growth behaviour from these two propping loads. The average retardation affected zones were $1.1 \mathrm{~mm}$ and $2.8 \mathrm{~mm}$ respectively. The amounts of life extension were negligible for both cases.

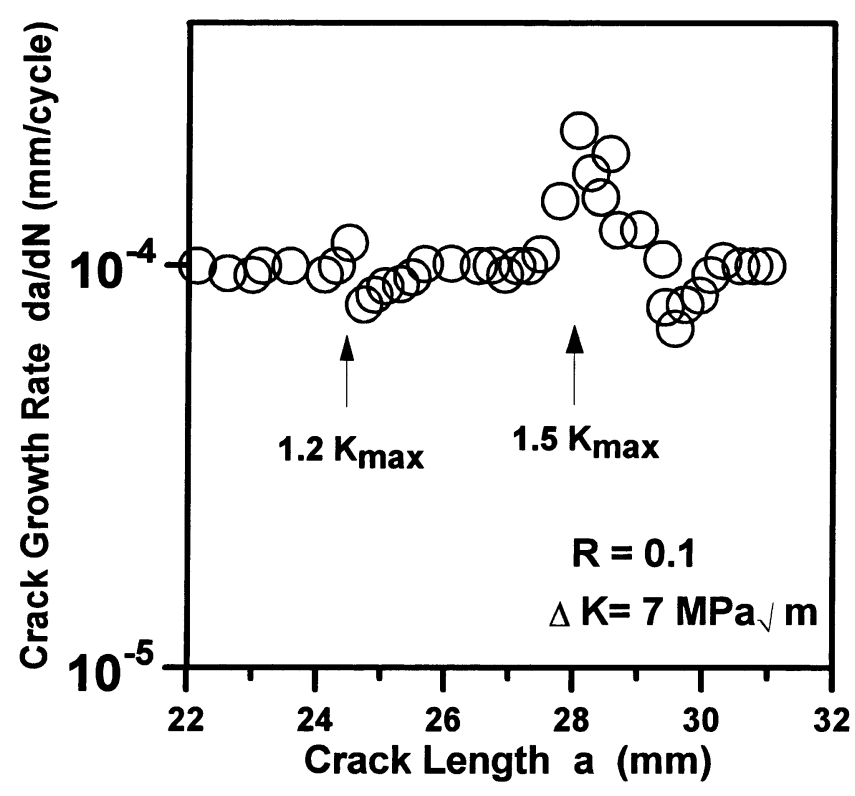

Fig. 1. Effect of prop-opening load alone on crack growth.

\subsection{Retardation caused by static mode infiltration}

\subsubsection{Effect of infiltration load level}

In this section we will compare the effects of static mode infiltration when the fatigue cracks were propped open with infiltration load levels (ILL) of $0.95,1.2$ and $1.5 K_{\max }$ respectively. Fig. 2 shows the effect of static mode plating of electroless nickel on to the fracture surface on crack growth behaviour on three identical specimens under an ILL of $0.95 K_{\max }$. The $R$ ratio employed was 0.1 . Before plating, cracks grew with a more or less steady rate of $10^{-4} \mathrm{~mm} /$ cycle. On resumption of cyclic loading after infiltration plating, growth retardation by over an order of magnitude was observed immediately. Growth rate then gradually increased from this minimum and it took crack growth increments of more than 10 $\mathrm{mm}$ for the cracks to gradually accelerate back to the previous steady state growth rate. The minimum growth rate achieved in Test 1 is a bit lower than the other two tests. The general retarded growth rates in Test 2 are slightly higher while that of Test 3 are slightly lower than that of Test 1 . All in all, the growth behaviour of the three specimens exhibited reasonable reproducibility.

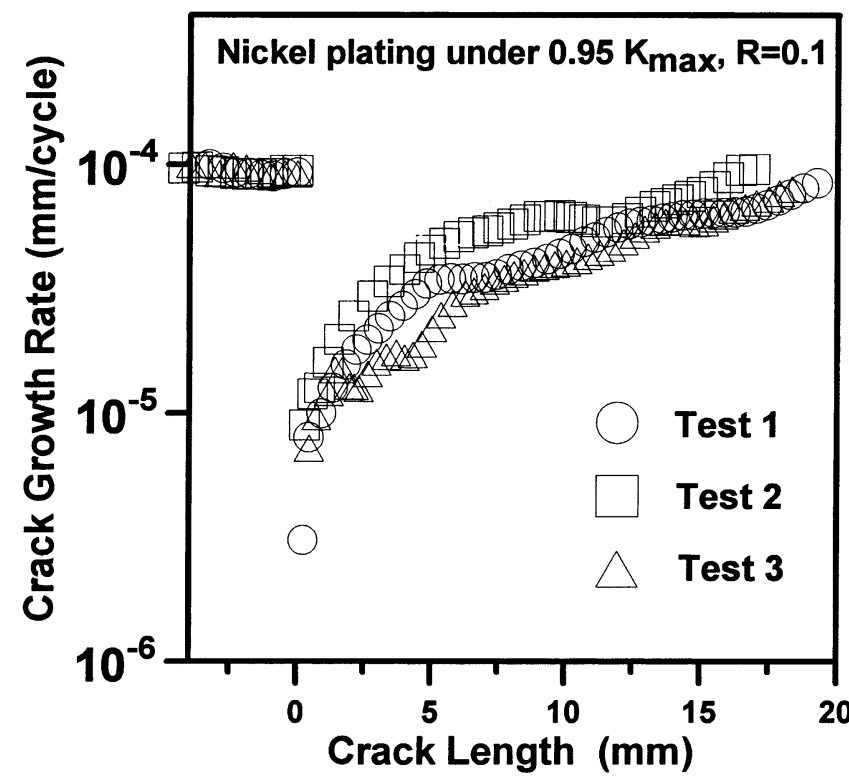

Fig. 2. Effect of static mode nickel-plating at $0.95 K_{\max }$ on crack growth in three identical specimens. 
The development of the measured degree of crack closure has the same trend as that of the growth rate. The relative severity of the decrease in crack opening levels and the growth increments required to regain the steady state condition closely matched the development of the growth rate transients in the respective tests. Fig. 3 compares the growth rate calculated (diamonds) from the measured $U$ values using Eq. (3) with the experimental observation (circles) for Test 1 . The initial retardation after nickel-plating as deduced from the measured closure is close to the observed growth rate. Thereafter, the predicted rates give heavy underestimation until the steady state is approached. This form of discrepancy is very typical of all the cases under static mode infiltration where crack growth continued to occur just after plating. By inserting a notch-mouth wedge, Garz and James [29] showed that contact below the measured crack opening load may still affect the crack growth rate. This suggests the applied loading below the measured closure point may somehow still contribute to the crack driving force. In overload retardation, a similar course of discrepancy development is observed when we compare the predicted growth based on the measured $U$ with the actual growth. The later is commonly attributed to the phenomenon of "discontinuous closure" $[10,11,30]$. Namely, as the crack grew away from the infiltrated wedge, crack flanks may come into contact with and be propped open by the wedge while the crack tip is still fully open. As a result, the measuring instrument indicated a crack closure load higher than the actual value seen by the crack tip, leading to an underestimation of growth rate using Eq. (3). This phenomenon will occur at a much smaller extent if the crack tip is very close to the infiltrated wedge, as the latter is nearly snuggly fitted to the crack opening profile.

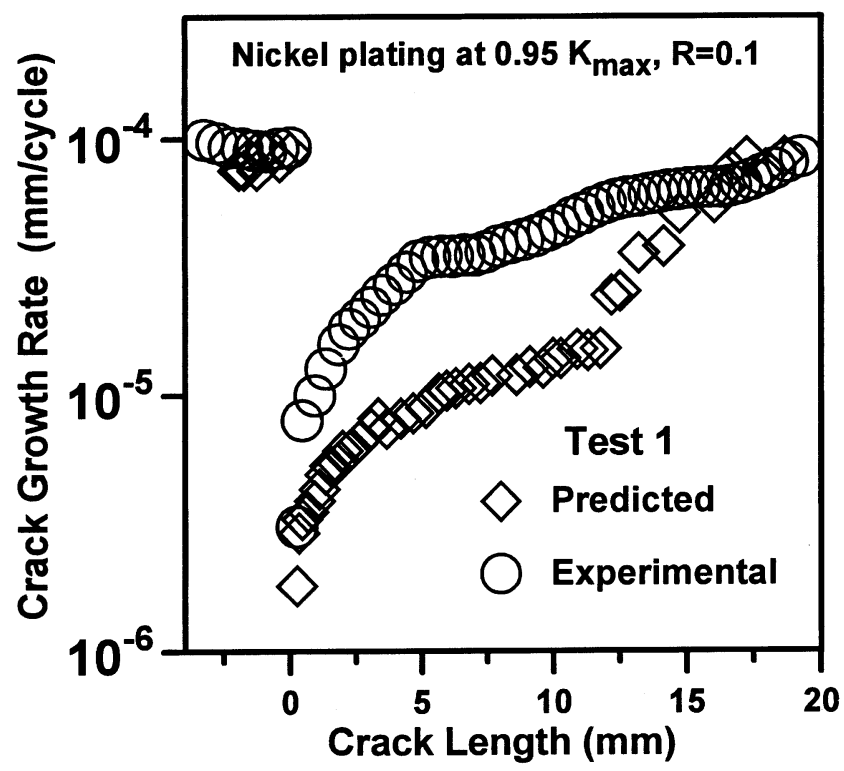

Fig. 3. Comparison between observed growth behaviour with prediction based on measured crack closure values.
When the crack tip is far away from the wedge this phenomenon is again minimal.

The respective maximum retardation ratio, minimum $U$ value reached, crack growth increment affected by the infiltration and the amount of life extension obtained are listed in Table 3. It should be noted that the infiltration plating process involved passing solution through a tiny space with highly irregular surface topography. Variation in the morphology of the resulting nickel wedge was inevitable. This would bring about experimental scatter in the immediate growth response as reflected in the retardation ratio and the minimum $U$ value achieved. More importantly, it also affected the subsequent development of crack closure and this has an accumulative effect on the amount of life extension. Thus slight variation in growth rate shown in Fig. 2 can result in marked difference in the amount of life extension reported in Table 3. This kind of scatter tended to decrease when the crack opening during infiltration was increased either under a higher infiltration load or by testing under a higher loading ratio.

Tests with the same cyclic loading conditions as above were repeated while infiltration repair was carried out with a higher ILL of $1.2 K_{\max }$. On resuming the cyclic loading, no crack growth was observed for two and a half million cycles. With the current measuring resolution of $0.01 \mathrm{~mm}$, this means that the crack growth rate has dropped below $4 \times 10^{-9} \mathrm{~mm} /$ cycle. As a result, crack growth was considered to have practically been arrested. On increasing the $R$ ratio to 0.2 , crack growth resumed but still at a reduced rate (see Fig. 4). The growth rates predicted using the measured crack closure values are again lower than the actual growth rates. Unlike the case above where crack continued to grow, the predicted rate when growth just restarts and at end of test are all lower than observed. These may be explained as follows: in the initial state of resumed growth, the infiltrated wedge was no longer "snuggly fitted" since the crack opening profile is already changed by the rise in the $R$ ratio. Again, raising the $R$ ratio increased the crack growth rate so that it returned to the original baseline value sooner. The crack growth increment to achieve this is much smaller than that in Fig. 3.

When the ILL was raised to $1.5 K_{\max }$, similar behaviour as that for $1.2 K_{\max }$ was observed, except that crack growth was not observed for another one million cycles even after increasing the $R$ ratio to 0.2. Resumption of crack growth at a reduced rate occurred only when the $R$ ratio was raised to 0.3 . Like the case in Fig. 4, the growth rates predicted from the measured crack closure values are all lower than the observed rates.

\subsubsection{Effect of loading ratio}

Fig. 5 compares the retardation effect at loading ratios $(R)$ of $0.1,0.3$ and 0.5 while the infiltration load level was held constant at $0.95 K_{\max }$. Key numerical values 
Table 3

Comparison of retardation effects at an infiltration load of $0.95 K_{\max }{ }^{a}$

\begin{tabular}{|c|c|c|c|c|c|c|c|}
\hline$R$ ratio & $\operatorname{ILL}\left(K_{\max }\right)$ & $\begin{array}{l}\text { No growth for } \\
\text { (cycles) }\end{array}$ & $\begin{array}{l}\text { Resumed } \\
\text { growth at } R^{\prime}\end{array}$ & $\begin{array}{l}\text { Retardation } \\
\text { ratio }\end{array}$ & $\begin{array}{l}\text { Affected growth } \\
\text { increment }(\mathrm{mm})\end{array}$ & Min. $U$ value & $\begin{array}{l}\text { Life extension } \\
\text { (cycles) }\end{array}$ \\
\hline \multirow[t]{5}{*}{0.1} & 0.95 & - & - & 0.033 & 20.08 & 0.122 & 430,000 \\
\hline & & - & - & 0.094 & 16.18 & 0.23 & 250,000 \\
\hline & & - & - & 0.078 & 18.07 & 0.21 & 450,000 \\
\hline & 1.2 & $2,500,000$ & 0.2 & 0.122 & 8.27 & $0.12^{\mathrm{b}} / 0.202$ & 277,300 \\
\hline & 1.5 & $3,500,000^{\mathrm{c}}$ & 0.3 & 0.233 & 5.28 & $\begin{array}{l}\sim 0 / \text { Gage } \\
\text { broken }\end{array}$ & 122,700 \\
\hline \multirow[t]{3}{*}{0.3} & 0.95 & - & - & 0.055 & 9.65 & 0.186 & 400,000 \\
\hline & 1.2 & $1,000,000$ & 0.4 & 0.045 & 8.7 & $0.07 / 0.123$ & 400,000 \\
\hline & 1.5 & $1,000,000$ & 0.4 & 0.012 & \multicolumn{3}{|c|}{ Accidently overloaded, no valid data } \\
\hline \multirow[t]{3}{*}{0.5} & 0.95 & - & - & 0.058 & 7.27 & 0.18 & 170,000 \\
\hline & 1.2 & $1,000,000$ & 0.6 & 0.275 & 3.8 & $0.14 / 0.48$ & 25,000 \\
\hline & 1.5 & $1,000,000$ & 0.6 & 0.132 & 4.8 & $\sim 0 / 0.322$ & 80,000 \\
\hline
\end{tabular}

a All Data in bold italic are for resumed growth at an increased load ratio $\left(R^{\prime}\right)$ after crack arrested for a number of cycles at the original load ratio $\left(R_{0}\right)$.

${ }^{\text {b }}$ Data before the slash are the minimum $U$ values right after infiltration, before the load ratio increase.

c This stands for 2.5 million cycles at $R=0.1$ followed by 1 million cycles at $R=0.2$.

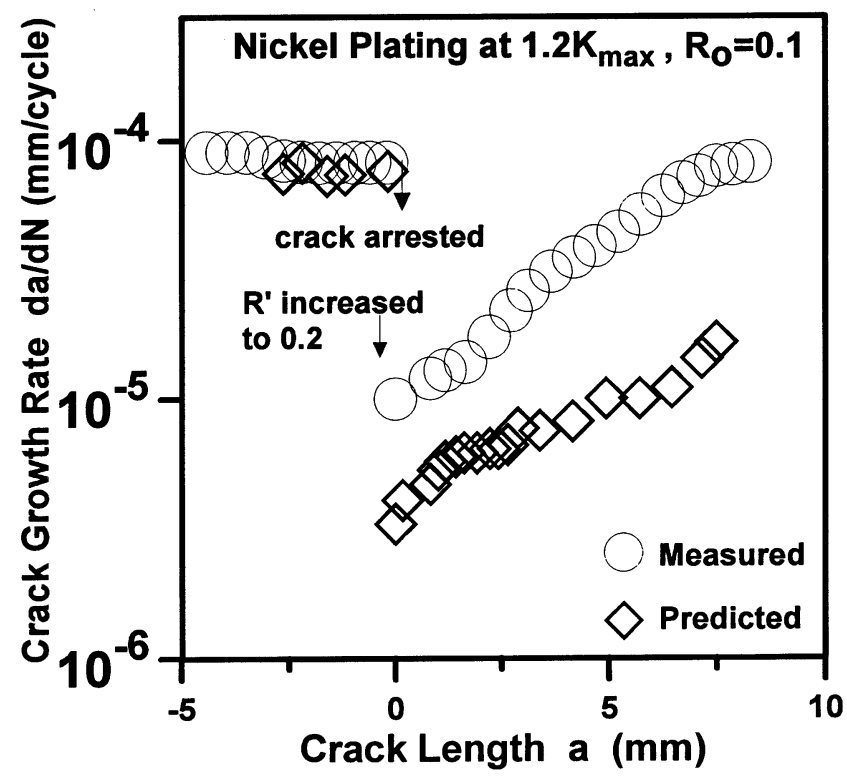

Fig. 4. Resumed growth on raising $R$ ratio to 0.2 after crack arrest following infiltration plating at $1.2 K_{\max }$.

about the retardation process are listed in Table 3. It was found that the maximum retardation effect was obtained at the lowest $R$ ratio of 0.1 . At this $R$ ratio, the minimum growth rate achieved was the lowest while the retardation affected crack growth increment was the longest. As the $R$ ratio increased, increasing minimum growth rates were obtained while the crack returned to the preinfiltration rate earlier. The discrepancies between predicted and observed rates match the trends remarked in the last section.

For infiltration load levels of 1.2 and $1.5 K_{\max }$, crack arrest have been obtained for all three load ratios tested. In these cases, to reduce the testing time, cracks were

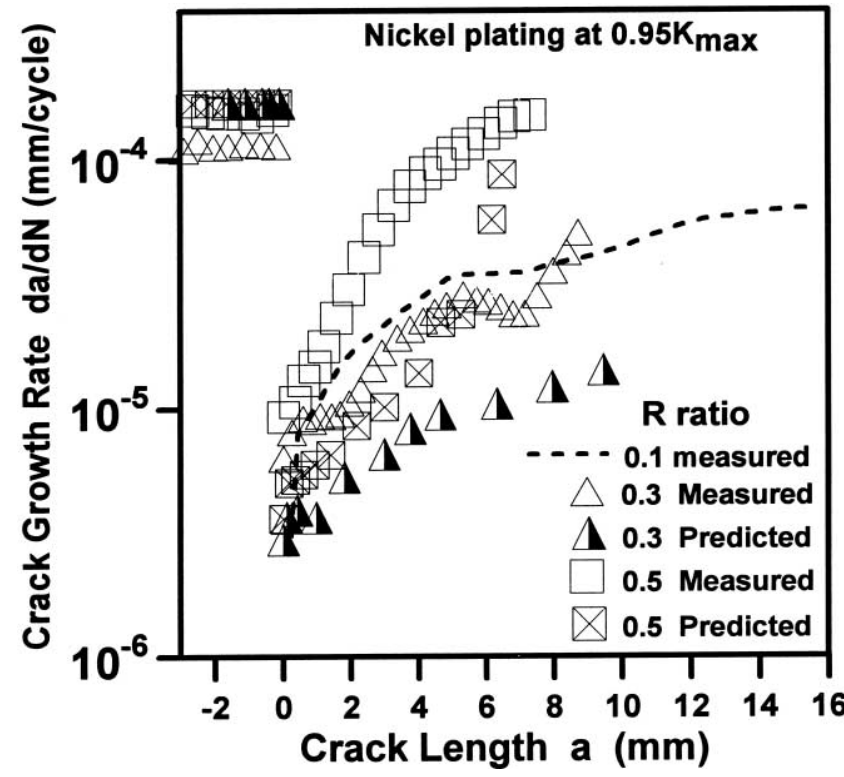

Fig. 5. Comparison of retardation effect at different $R$ ratios under an ILL of $0.95 K_{\max }$.

considered to have arrested if no growth has been observed after one million cycles (corresponds to a growth rate smaller than $1 \times 10^{-8} \mathrm{~mm} /$ cycle). Resumption of crack growth occurred if the load ratio was increased by at least 0.1 above the original $R_{0}$. Fig. 6 summarizes the resumed growth behaviour for $R$ ratios ranging from 0.1 to 0.5 at ILLs' above $K_{\max }$. After raising the $R$ ratio, the crack started to grow immediately but still at a reduced rate. For the same original $R$, this reduced rate is lower for the higher ILL of $1.5 K_{\max }$ than that for the lower ILL of $1.2 K_{\max }$. This generalization is apparently violated in the case of $R=0.1$. However, it must be borne in mind that for this case, crack growth is still absent 


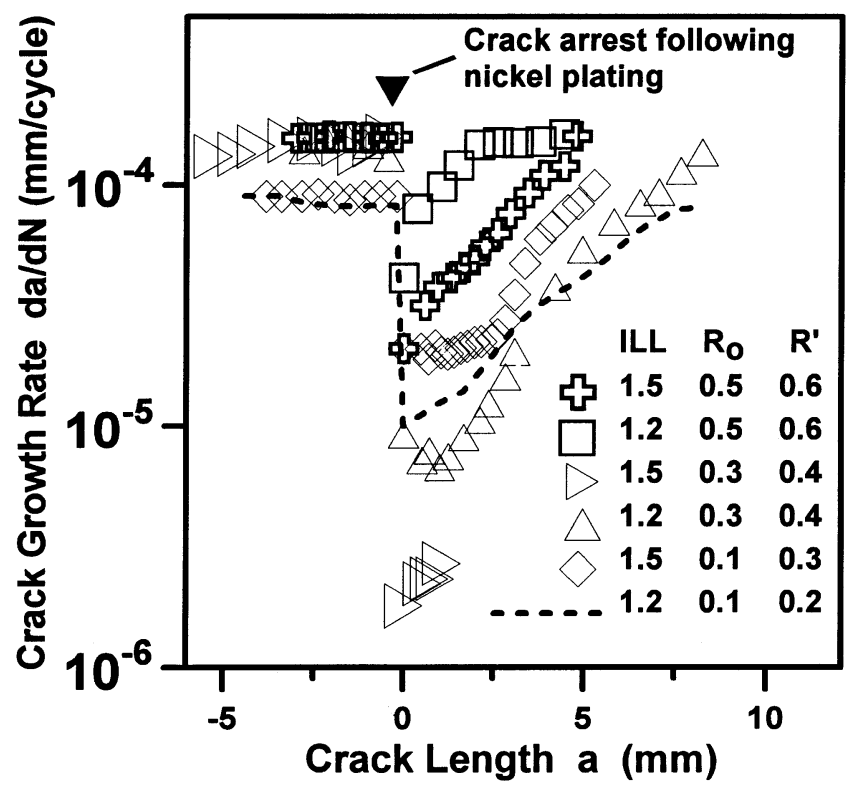

Fig. 6. Comparison of retardation following nickel-plating at ILL above the maximum cyclic loading. $\left(R_{0}\right.$ is the original $R$ ratio whereby all infiltrated cracks become arrested. $R^{\prime}$ is the $R$ ratio at which crack growth resumed.)

when $R$ is raised by 0.1 . The reduced rate reported in Fig. 6 is actually the result after raising $R$ further from 0.1 to 0.3 . Apart from this, unlike the cases for an ILL of $0.95 K_{\max }$, the maximum retardation effect was obtained at $R_{0}=0.3$. This is followed by those with $R_{0}=0.1$. The minimum rates are highest for $R_{0}=0.5$. This may be understood as follows: with a higher $R$ ratio, the crack opening was larger and the passage of the electroplating solution was easier initially and a thicker wedge would be formed. However, subsequent crack opening on resumption of fatigue loading was also larger and this may partly or totally offset the beneficial repair effect of a thicker infiltrated wedge. This offset effect may be overridden by infiltration plating at a higher ILL. The resulting compromise gives the different trends of resumed growth under the different load ratio and ILL combinations.

\subsubsection{Effect of loading history}

In the last section, the load ratios were raised only after a million of dormant load cycles at the original $R_{0}$. To shed more light on the effect of load history variations, those tests with original $R_{0}$ equals 0.1 were repeated. Immediately following infiltration plating, the respective $R^{\prime}$ for which crack growth restarted was employed. Key numerical values about the retardation process are listed in Table 4. Fig. 7 shows the comparison between this new loading history with that in the last section for an ILL of $0.95 K_{\max }$. It can be seen that if the original $R_{0}$ of 0.1 was maintained, the maximum retardation achieved will be more severe than if $R^{\prime}=0.2$ was employed. In the subsequent growth development, the acceleration back to steady state values for the growth under $R=0.2$ is slightly faster than that under $R=0.1$. When the ILL is $1.2 K_{\max }$ (see Fig. 8), in contrast to the resumption of crack growth under $R^{\prime}=0.2$ following one million dormant cycle at $R_{0}=0.1$, immediate application of $R^{\prime}=0.2$ after infiltration plating resulted in a non-propagating crack for at least one million cycles. Crack growth only resumed on increasing $R$ further to 0.3 . Although the resumed growth for the two situations was under different load ratios, the growth behaviour is more or less the same for the initial couple of millimeters growth increment. Thereafter, the growth under $R=0.3$ seems to accelerate faster. Unfortunately the test was interrupted by an accidental power failure. For the cases when the ILL is $1.5 K_{\max }$ (see Fig. 9), the growth data presented are both under an $R^{\prime}$ of 0.3 . However, the dotted line data are obtained after the crack remaining dormant for 2.5 million cycles under the original $R_{0}$ of 0.1 followed by 1 million cycles at $R^{\prime}=0.2$. Data represented by open circles are collected when an $R^{\prime}=0.3$ was applied immediately following infiltration plating. It is clear that the dotted line case has a higher minimum rate and accelerated faster back to the steady state values than the open circle case.

Summarizing the above observation, although an infiltrated crack may lie dormant at a low enough load ratio, there are probably changes in the infiltrated nickel wedge, which reduce their effectiveness in retarding the fatigue crack later on. An examination of the crack closure development during the dormant cycles revealed this. The courses of development of crack closure following infiltration plating in the various tests may be grouped into three categories: (i) those in which the crack continued to grow after infiltration; (ii) crack growth resumed on changing the loading condition followed a non-propagation period; and (iii) crack stopped growing after infiltration. Typical examples for each of these categories are shown in Fig. 10(a), (b) and (c) respectively.

For cracks which continued to grow after infiltration plating (see Fig. 10(a)), there is a slight drop in $U$ in the first few tens to few thousand cycles. The $U$ values then increase steadily as the crack tip moves away from the infiltrated wedge. Fig. 10(b) shows the development of crack closure for resumed crack growth under raised $R$ ratio following a period of crack arrest, $U$ values dropped initially in the first hundred cycles or so. It then remained more or less constant for a crack growth increment of $1.6 \mathrm{~mm}$. Thereafter, it increases steadily.

The initial drop in $U$, or increase in the degree of crack closure, is thought to be caused by the infiltrated nickel being squeezed towards the crack tip. In fact it has sometimes been observed that traces of the nickel wedge were squeezed out along the crack flank.

Fig. 10(c) shows the development of crack closure during the 2.5 million dormant cycles in the specimen with ILL equals $1.2 K_{\max }$ and $R=0.1$. Although the vari- 
Table 4

Retardation responses when precracked at $R=0.1$ and cycled at higher $R$ 's right after infiltration

\begin{tabular}{|c|c|c|c|c|c|c|}
\hline $\begin{array}{l}R \text { ratio for } \\
\text { precracking }\end{array}$ & $\operatorname{ILL}\left(K_{\max }\right)$ & $\begin{array}{l}R^{\prime} \text { right after } \\
\text { infiltration }\end{array}$ & Retardation ratio & Min. $U$ value & $\begin{array}{l}\text { Affected growth } \\
\text { increment (mm) }\end{array}$ & $\begin{array}{l}\text { Life extension } \\
\text { (cycles) }\end{array}$ \\
\hline \multirow[t]{3}{*}{0.1} & 0.95 & 0.2 & 0.106 & 0.2 & 14.33 & 400,000 \\
\hline & 1.2 & $0.2 / 0.3^{\mathrm{a}}$ & arrested/0.086 & $0.064 / 0.14$ & \multicolumn{2}{|c|}{ Accidental power failure, no valid data } \\
\hline & 1.5 & 0.3 & 0.057 & 0.11 & 11.75 & 750,000 \\
\hline
\end{tabular}

a Data before the slashes are quantities right after infiltration. Since crack arrest has occurred, the load ratio $R^{\prime}$ was further increased. Data in bold italic following the slashes are quantities after load ratio increase.

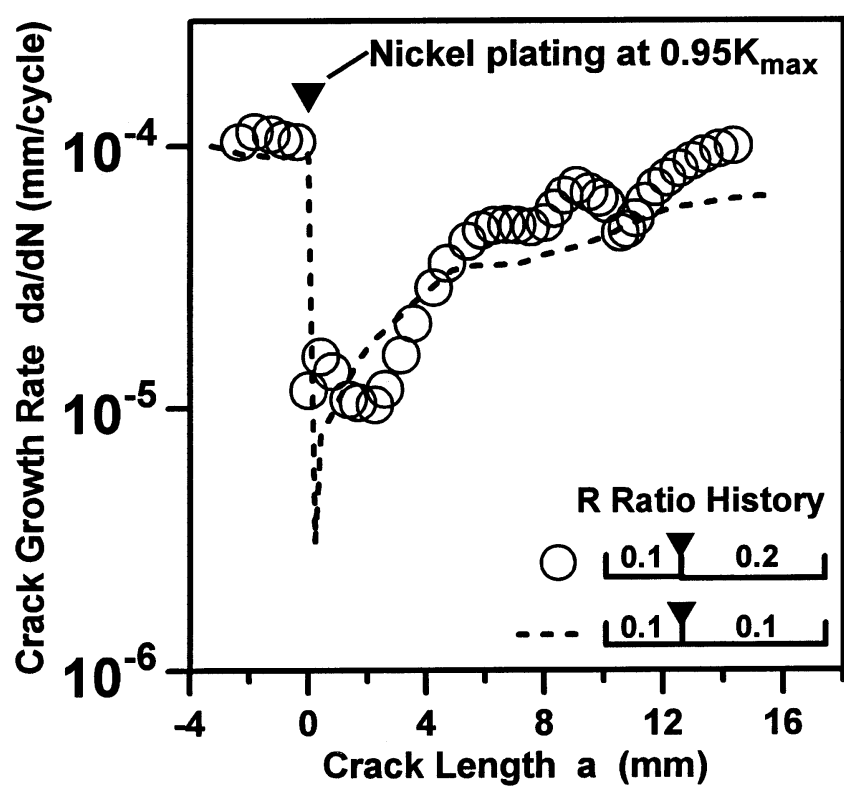

Fig. 7. Comparison of retardation behaviour for two different load ratio histories at an ILL of $0.95 K_{\max }$.

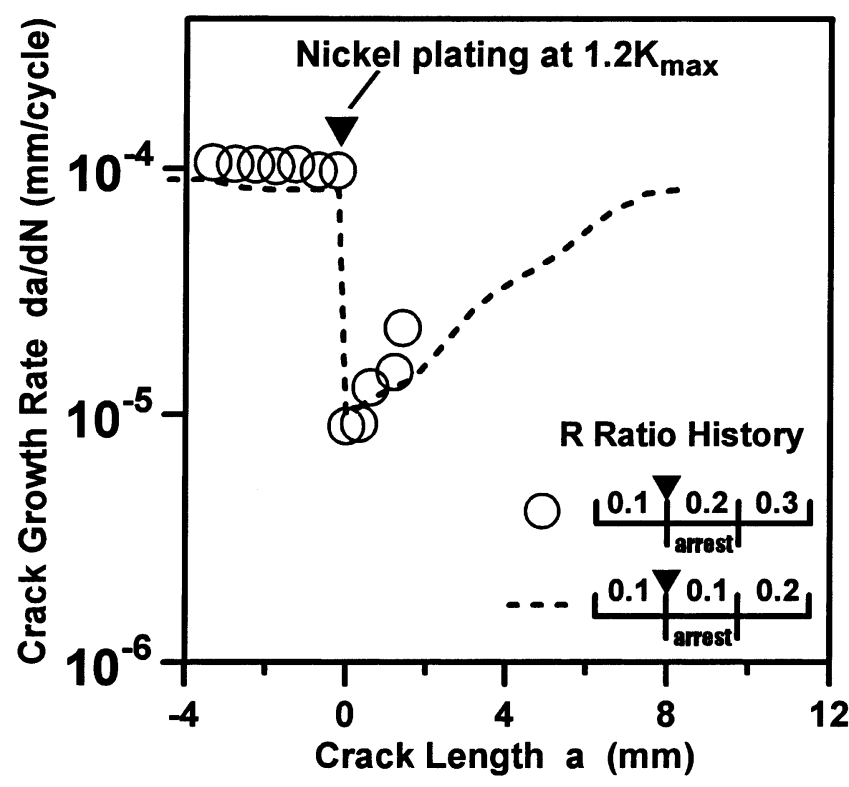

Fig. 8. Comparison of retardation behaviour for two different load ratio histories at an ILL of $1.2 K_{\max }$.

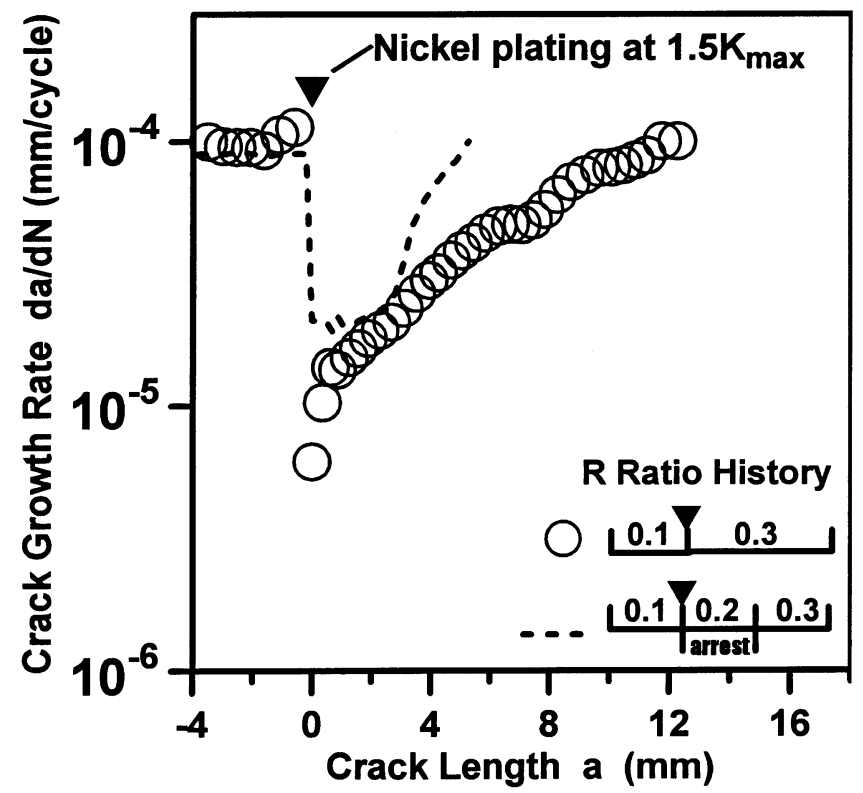

Fig. 9. Comparison of retardation behaviour for two different load ratio histories at an ILL of $1.5 K_{\max }$.

ation of $U$ with cycles more or less amounts to the degree of uncertainty, a weak increasing trend can be made out. This may reflect that although no crack growth has occurred, the thickness of the infiltrated nickel wedge is being reduced by the repeated compression during unloading. This may be the explanation for the load ratio history effect exhibited in Figs. 8 and 9. This effect may also occur to a lesser extent in the cases where cracks continued to grow after infiltration. However, in these cases, $U$ will invariably increase as the crack tip moves away from the infiltrated wedge.

Summarizing the results for static mode infiltration, it can be concluded that intense retardation effect can be derived just after infiltration if the propping load is high enough. If the propping load level is lower than the maximum cyclic load, the thickness and proximity of the wedge to the crack tip is not enough to arrest the crack straight away. In such a case, the retardation effect dies down quickly. Furthermore, the electroless plated nickel wedge probably suffers slight reduction in thickness as a result of repeated crack flank compression. All these effects are detrimental to the achievement of a good 

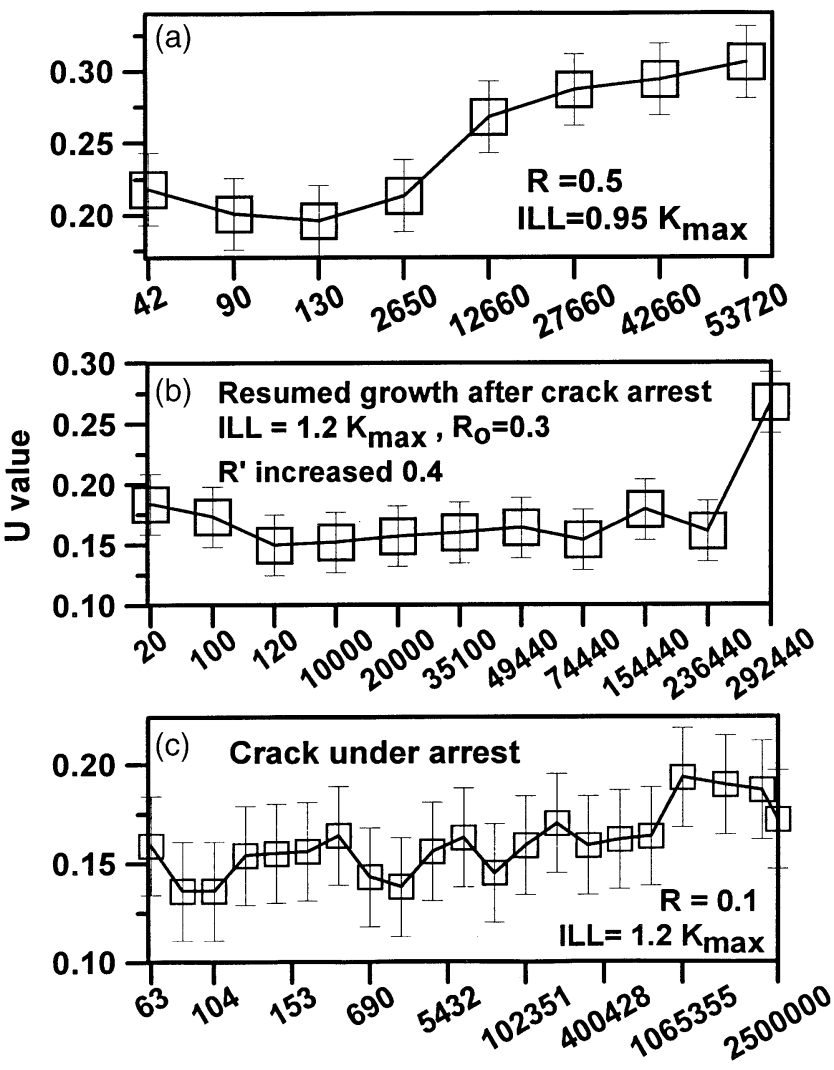

\section{Number of cycles after infiltration or after increasing $\mathbf{R}$}

Fig. 10. Development of crack closure after infiltration plating for a crack that (a) continued to grow; (b) arrested and resumed growth on increasing $R$; (c) remained dormant.

fatigue life extension. If the thickness and extent of the wedge can be constantly replenished, we can expect to achieve a much better life extension. To these ends the effect of dynamic infiltration were investigated in the following.

\subsection{Retardation caused by dynamic infiltration}

Fig. 11 compares the retardation behaviour induced by continuous in-situ infiltration plating of nickel under different loading frequencies. At $1 \mathrm{~Hz}$, crack growth rate dropped gradually as infiltration plating started. After a growth increment of $\sim 3 \mathrm{~mm}$, growth rate seemed to have settled down to a steady value of $\sim 3 \times 10^{-6} \mathrm{~mm} /$ cycle. At this rate it took about four days to grow the crack for one millimeter. Under this prolonged use, the heater for the electrolyte failed and the test was stopped prematurely. Similar growth behaviour occurred at $5 \mathrm{~Hz}$, with the steady state retarded growth rate settled at $\sim 6 \times 10^{-6}$ $\mathrm{mm} /$ cycle, achieved after a growth increment of $\sim 3.5$ $\mathrm{mm}$. In both cases, the amount of retardation was more than one order of magnitude. At $10 \mathrm{~Hz}$, it took only 1 $\mathrm{mm}$ growth after infiltration plating started to reach steady state. The retarded growth rate was $\sim 4.5 \times 10^{-5}$

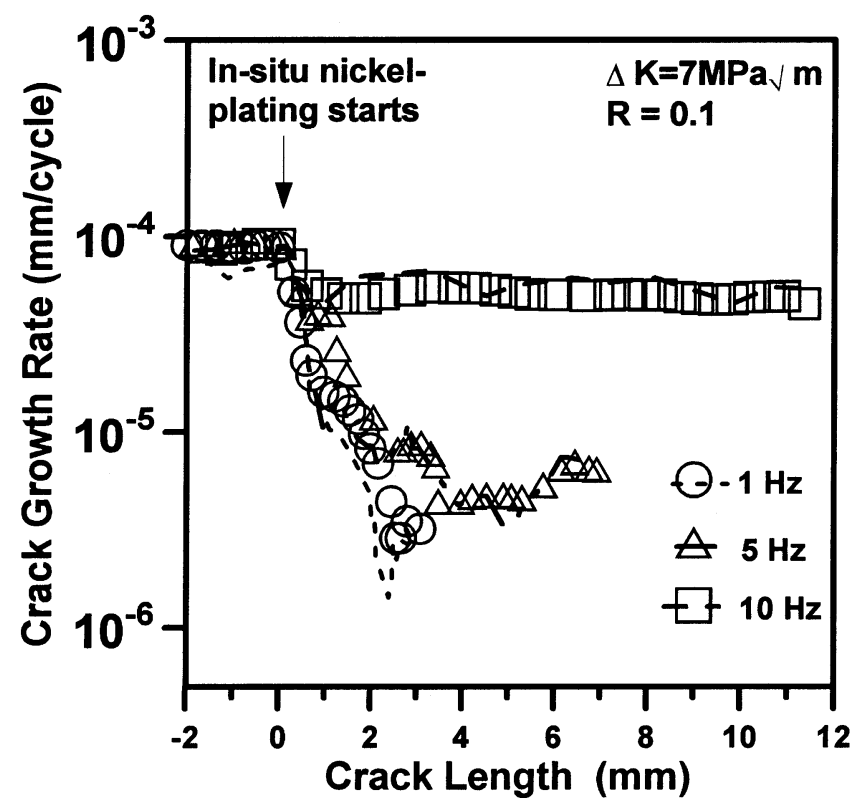

Fig. 11. Comparison of crack retardation behaviour induced by dynamic infiltration plating under different loading frequencies.

$\mathrm{mm} /$ cycle. The retardation effect of dynamic infiltration plating decreases with increase in loading frequency, presumably because the rate of wedge build-up fails to catch up with the crack growth. In all three cases, growth rates deduced from the measured closure values (respective broken lines in Fig. 11) agree reasonably well with the observed rates. This is in marked contrast to all the static infiltration cases where predicted rates are in general all significantly below the observed rates. The cause of this may be due to the fact that alternate opening and closing of the crack has a pumping effect so that electrolyte can be plated to a closer proximity to the crack tip. Moreover, this wedge is continuously replenished as the crack tip moves forward, avoiding the phenomenon of "discontinuous closure" mentioned before.

By comparing the crack length versus number of cycles curves (Fig. 12) one can assess the relative effect of retardation behaviour induced by infiltration plating of nickel under static and dynamic infiltration at different frequencies. Although the $1 \mathrm{~Hz}$ curve stopped prematurely, its trend suggests that it is going to have the longest fatigue life. Next comes the $5 \mathrm{~Hz}$ case which got a slightly lower life extension than the $1 \mathrm{~Hz}$ case. Within a small crack growth increment just after infiltration, the intensity of retardation of the static mode repair seems to be comparable or even better than that in the $1 \mathrm{~Hz}$ case. However, in the long run, its retardation effect died down and the amount of life extension was much less than that at $5 \mathrm{~Hz}$. Continuous infiltration plating under $10 \mathrm{~Hz}$ produced the least effect among the four cases. 


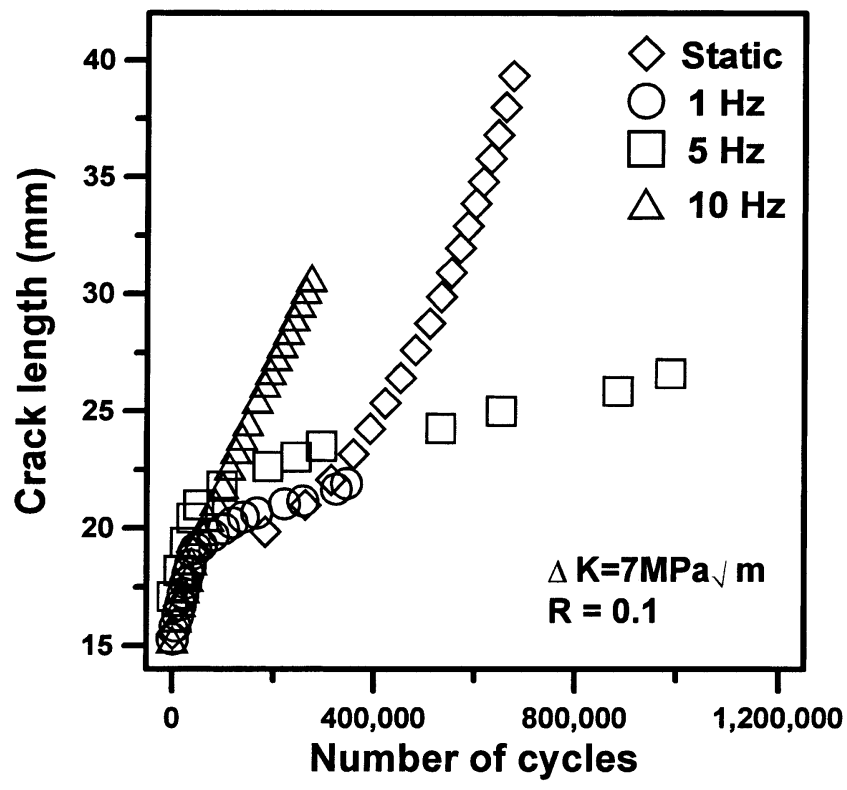

Fig. 12. Comparison of fatigue lives under static and different dynamic infiltration conditions under $R=0.1$.

\subsection{Retardation caused by alternate static and dynamic infiltration}

The above result showed that in-situ dynamic infiltration plating is capable of retarding and may thus repair a fatigue crack. This mode is probably more relevant to in-service applications than the static mode plating. However, as shown above, if the service load frequency is high, the retardation so derived may be too small to be of practical interest. If we combined the initially strong retardation of the static infiltration with the continuously replenishing dynamic mode, then even though under a high loading frequency, the retardation effect may still be useful for real life fatigue cracks. This postulation is put to test in the following specimens.

Fig. 13 shows the effect of applying a static mode infiltration plating at $0.95 K_{\max }$ followed by continuous dynamic plating under a loading frequency of $10 \mathrm{~Hz}$. The initial retardation obtained $\left(\sim 3.5 \times 10^{-6} \mathrm{~mm} /\right.$ cycle $)$ is comparable to the static mode plating alone cases as shown in Fig. 2. However, as the crack grew on, its rate dropped slightly yet continuously until it became more or less steady at $\sim 2 \times 10^{-6} \mathrm{~mm} /$ cycle. This represents a drop of nearly two orders of magnitude in growth rate. Moreover, the growth rates predicted on the measured $U$ values agree closely with the measured rates. Fig. 14 shows a similar case except that the infiltration plating here was not totally successful. The latter fact is reflected in the higher initial rate $\left(\sim 5.5 \times 10^{-6} \mathrm{~mm} /\right.$ cycle $)$ after plating and that the predicted rates are consistently lower than the observed. Nevertheless, under the subsequent dynamic infiltration, the growth rate has dropped to $2.4 \times 10^{-6} \mathrm{~mm} /$ cycle after a crack growth increment of 7 $\mathrm{cm}$. This suggests that good retardation is still achievable

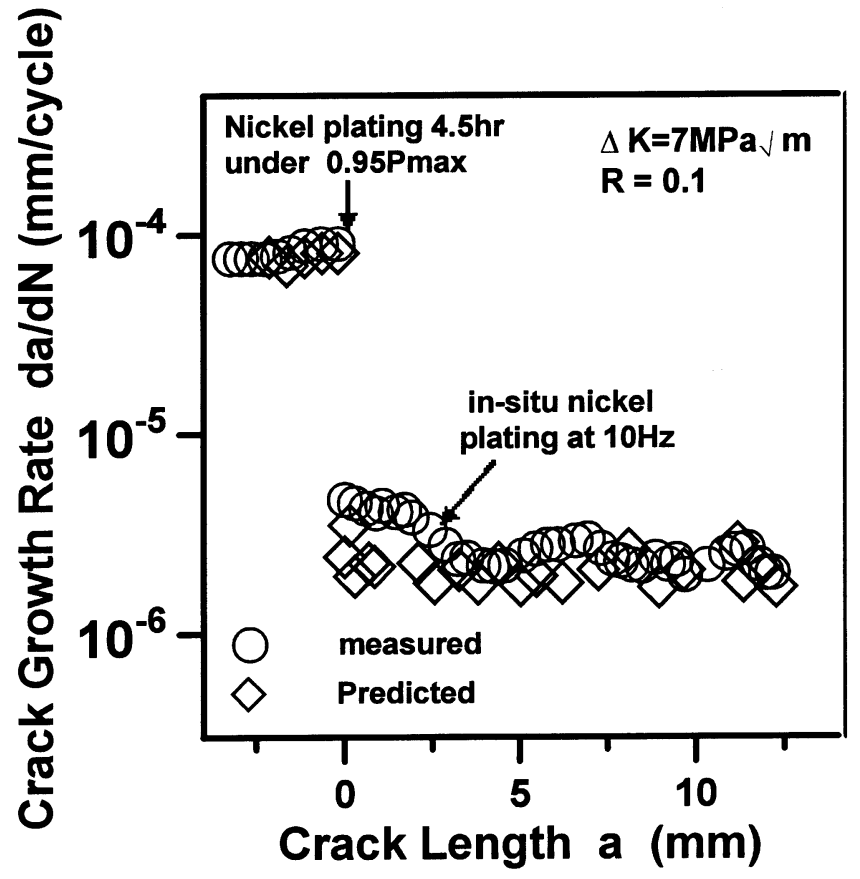

Fig. 13. Retardation behaviour induced by one static infiltration plating followed by dynamic plating at $10 \mathrm{~Hz}$.

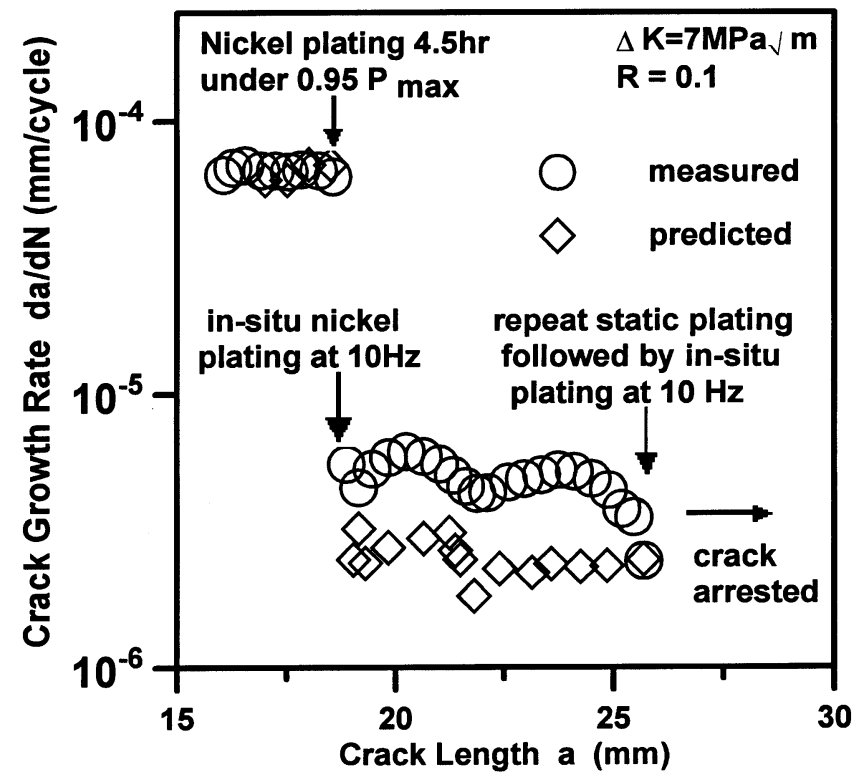

Fig. 14. Retardation behaviour induced by two static infiltration platings with dynamic plating at $10 \mathrm{~Hz}$ in between.

even if the initial static infiltration was not totally satisfactory. A static mode infiltration at $0.95 K_{\max }$ was then applied followed by the resumption of cyclic loading and dynamic infiltration. From the point where cyclic loading was resumed, no observed growth occurred for one million cycles.

Fig. 15 shows the effect of a series of alternate static and dynamic infiltration. Unlike the previous two tests, dynamic instead of static infiltration was applied just 


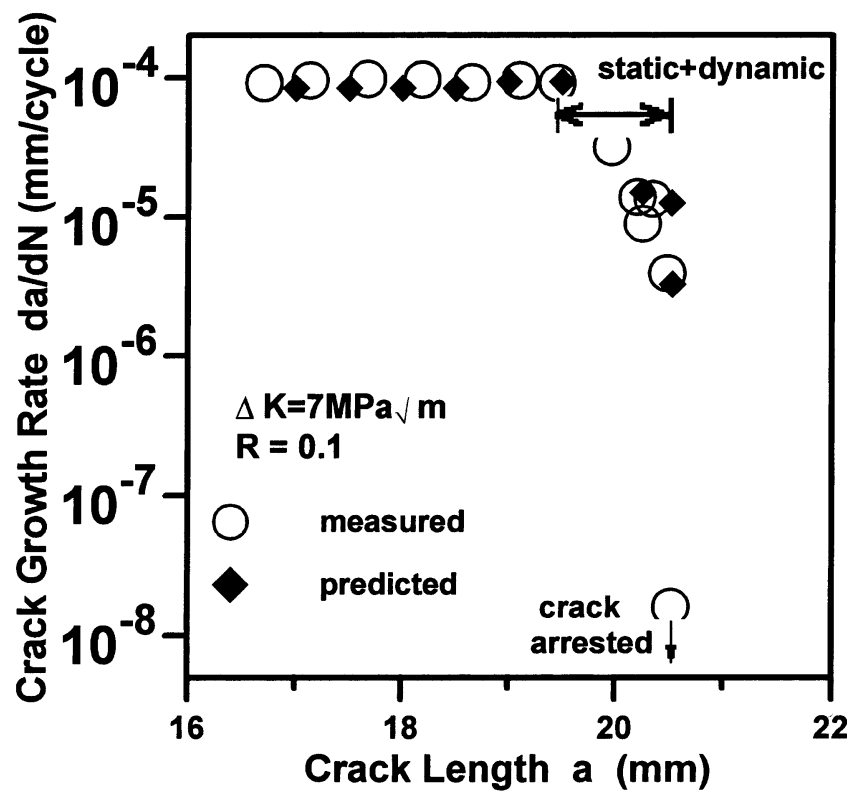

Fig. 15. Retardation behaviour induced by alternate static and dynamic infiltration plating.

after precracking for a period of 7500 cycles. The test was then stopped at a random loading between 0.1 to 1 $K_{\text {max }}$ for static infiltration to be carried out. When no more electrolyte seeped through, cyclic loading and dynamic infiltration was again applied for another 7500 cycles. This process of alternate dynamic and static infiltration was repeated. It can be seen from Fig. 15 that the crack growth rate dropped steeply. After seven repetitions of alternate infiltration, the growth rate appeared to have dropped below $3 \times 10^{-7} \mathrm{~mm} /$ cycle. Excluding the precracking period, the total time elapsed was about ten hours up to this point. Infiltration was then stopped and cyclic loading only was maintained for one and a half million cycles to ascertain that crack arrest has really occurred. In this test, the growth rates evaluated from the crack closure values match well with the observed growth rates.

\section{Conclusions}

Electroless infiltration plating of nickel into a fatigue crack has been shown to be able to retard the crack and bring about life extension. By propping open the crack with $95 \%$ of the maximum cyclic loading, immediate retardation by more than one order of magnitude from a baseline growth rate of $10^{-4} \mathrm{~mm} /$ cycle has been achieved under all the load ratios $(0.1-0.5)$ tested. If the propping load was increased to $120 \%$ or higher, immediate crack arrest occurred. In these cases, even when the load ratios were increased by 0.1 , cracks still grew with a reduced rate at least one order lower than the baseline. At $150 \%$ propping load, it even took a 0.2 increase in load ratio to make the crack grow again. By pre-cracking at a lower load ratio (0.1) and growing the infiltrated crack at a higher ratio $(0.2$ or 0.3$)$, it can be shown that the geometry of the infiltrated wedge had been changing even if the crack has remained dormant.

Continuous infiltrating plating at loading frequency of $5 \mathrm{~Hz}$ or below retarded the growth rate by nearly two orders of magnitude. The retardation effect at $10 \mathrm{~Hz}$ was slight. Static mode plating for $4.5 \mathrm{~h}$ has good short-term retardation effect but the long-term effect is inferior to that of dynamic plating under $5 \mathrm{~Hz}$.

The best retardation effect was obtained by applying alternate on-line dynamic infiltration and static mode infiltration. This can effectively bring a growing fatigue crack to arrest in a short growth increment even at a loading frequency of $10 \mathrm{~Hz}$.

\section{Acknowledgements}

The authors gratefully acknowledge the financial support provided by the National Science Council under the projects NSC-88-2212-E-002-057 and NSC-89-2212-E002-031.

\section{References}

[1] von Euw EJF, Hertzberg RW, Roberts R. Delay effects in fatigue crack propagation. Stress analysis and growth of cracks. In: Proceedings of the 1971 National Symposium on Fracture Mechanics, Part I, ASTM STP 513. American Society for Testing and Materials, 1972:230-59.

[2] Christensen RH. Metal fatigue. New York: McGraw-Hill, 1959.

[3] Schijve J, Broek D. Crack propagation. The results of a test programme based on a gust spectrum with variable amplitude loading. Aircraft Engng 1962;34:314-6.

[4] Jones RE. Fatigue crack growth retardation after single cycle overload in Ti-6Al-4V titanium alloy. Engng Fract Mech 1973;5:585-604.

[5] Suresh S. Crack growth retardation due to micro-roughness: a mechanism for overload effects in fatigue. Scripta Metallurgica 1982;16:995-9.

[6] Suresh S. Micromechanisms of fatigue crack growth retardation following overloads. Engng Fract Mech 1983;18(3):577-93.

[7] Elber W. Fatigue crack closure under cyclic tension. Engng Fract Mech 1970;2:37-45.

[8] Elber W. The significance of fatigue crack closure. In: Damage tolerance in aircraft structures, ASTM STP 486. American Society for Testing and Materials, 1971:230-42.

[9] Shin CS, Fleck NA. Overload retardation in a structural steel. Fat Fract Engng Mater Struct 1987;9(5):379-93.

[10] Fleck NA. Influence of stress state on crack growth retardation. In: Fong JT, Fields RJ, editors. Philadelphia: American Society for Testing and Materials, 1988:157-83.

[11] Shin CS, Hsu SH. On the mechanism and behaviour of overload retardation in AISI 304 stainless steel. Int J Fat 1993;15(3):181-92.

[12] Kitagawa H, Toyohira S, Ikeda K. A new method of arresting fatigue crack growth by artificial wedge. In: Sih GC, Valluri SR, editors. Int Conf on Fract Mech in Engng Appl, The Netherlands, 1979:281-93. 
[13] Vecchio RS, Crompton JS, Hertzberg RW. Anomalous aspects of crack closure. Int J Fract 1986;31:R29-33.

[14] Hertzberg RW, Newton CH, Jaccard R. Crack closure: correlation and confusion. ASTM STP 982. American Society for Testing and Materials, 1988:139-48.

[15] Shin CS, Hsu SH. Fatigue life extension by an artificially induced retardation mechanism. Engng Fract Mech 1992;43(4):677-84.

[16] UR-Rehman A, Thomason PF. The effect of artificial fatigue crack closure on fatigue crack growth. Fat Fract Engng Mater Struct 1993;16(10):1081-90.

[17] Shin CS, Huang KC, Li RZ. Artificial retardation of fatigue crack growth by the infiltration of cracks by foreign materials. Fat Fract Engng Mater Struct 1998;21:835-46.

[18] Sharp PK, Clayton JQ, Clark G. Retardation and repair of fatigue cracks by adhesive infiltration. Fat Fract Engng Mater Struct 1997;20(4):605-14.

[19] Wang YY, Zho MX, Feng DQ. A study of retarding fatigue crack growth using an artificial wedge. Fat Fract Engng Mater Struct 1993;16(3):363-76.

[20] Shin CS, Cai CQ. A model for evaluating the effect of fatigue crack repair by the infiltration method. Fat Fract Engng Mater Struct 2000:23 (in press).

[21] Shin CS, Wang CM, Song PS. Fatigue damage repair - a comparison of some possible methods. Int J Fat 1996;18(8):535-46.
[22] Song PS, Wang CM, Shin CS. An investigation on various infiltration methods for fatigue crack repair. In: Proc. FENDT ' 94 and ROCSNT Ninth Annual Conference, Taipei, ROC, 1994:221-8.

[23] Sheu BC, Song PS, Shin CS. The effect of infiltration induced crack closure on crack growth retardation. Scripta Metallurgica et Materialia 1994;31(10):1301-6.

[24] Song PS, Hwang S, Shin CS. Effect of artificial closure materials on crack growth retardation. Engng Fract Mech 1998;60(1):4758 .

[25] James MN, Smith GC. Surface microcrack closure in fatigue: a comparison of compliance and crack sectioning data. Int J Frac 1983;22:R69-75.

[26] Song PS, Hwang S, Shin CS. Enhancement in fatigue life through electroplated nickel-induced crack closure. J Chinese Soc Mech Engng 1996;17(6):601-7.

[27] Song PS, Chow HS, Sheu BC. Deposition of plating materials to improve crack growth life. Int Jnl Fatigue 2001 (in press).

[28] Kikukawa M, Jono M, Tanaka K. Fatigue crack closure behaviour at low stress intensity level. Proc ICM2, Boston, 1976:254-77.

[29] Garz RE, James MN. Observation on evaluating fatigue crack closure from compliance traces. Int J Fat 1989;11(6):437-40.

[30] Brahma KK, Dash PK, Dattagura B. Observation of crack closure using a crack mouth opening displacement gauge. Int $\mathbf{J}$ Fat 1989;11(1):37-41. 